\title{
Business Model Framework for Using Real-Time Process Data for Design Decision Making
}

\author{
Matty Janssen and Paul Stuart \\ École Polytechnique de Montréal, Department of Chemical Engineering \\ PO Box 6079, succ. Centre Ville, Montréal (QC), Canada, H3C 3A7 \\ paul.stuart@polymtl.ca
}

\begin{abstract}
In recent years real-time data management systems have become commonplace at pulp and paper mills, and mills seek to use this important resource for improved operation of production facilities as well as for business decision-making. This paper presents a comprehensive and holistic approach to business modeling in which real-time process data, cost data, and environmental data are used in a "bottom-up" manner to exploit their potential for process decisionmaking. The paper describes a hypothetical case study in which the business model concept is illustrated by application to a process design problem at an integrated newsprint mill.
\end{abstract}

\section{Background}

\subsection{Real-time data usage at pulp and paper mills}

In recent years, real-time process data have become widely-available at pulp and paper mills through the implementation of mill-wide data management systems that acquire, store, and manage data. In addition to data management systems, mills are also implementing systems that capture business transactions, track product quality, or help manage human resources. Together, these systems help pulp and paper mills to better understand their operations and tackle critical problems - both tactical and strategic. Process analysis can be executed taking into account the whole mill, instead of only a single unit or a small system. Process performance can be improved using a combination of process efficiency metrics, cost metrics and environmental metrics.

Information management systems (IMS) have been implemented since the late 1970s and have been expanding over time as existing or new subsystems or applications were integrated. An IMS is a mill-wide data and information repository, which supports multiple applications that provide the information required by different mill stakeholders such as managers, engineers, and operators. Distributed control systems (DCS) and maintenance systems were the first to be implemented mill-wide. However, these systems were capable of gathering, but not storing large quantities of data. In recent years, packages such as PI by Osisoft Inc. [15] or MOPS by MOPS Systems [26] (which focus on process data), and SAP [23] or PeopleSoft [17] (which focus on business data), have been implemented in the industry, either mill-wide or company-wide.

Several examples of IMS applications in the pulp and paper industry have been reported in the literature (Table 1).Table 1 illustrates the wide range of IMS applications. However there remain many more opportunities to be exploited. The examples in Table 1 can be characterized by a "top-down" or reactive approach to problem solving. However, the opportunity to extract process knowledge from the data is not fully exploited. For attaining full exploitation, pulp and paper mills and companies can alternatively use a "bottom-up" approach, which incorporates knowledge from the interpretation of available data in real-time for mathematical modeling of processes in the mill. Process integration techniques generally use this "bottom-up" approach. For instance, process data can be used in many mathematical optimization applications to improve process decision-making.

\subsection{Current pulp and paper industry priorities}

The pulp and paper industry currently faces numerous and significant challenges. For example Leaver \& Scott [14] summarize some key issues related to industry image on the stock markets, capital intensive infrastructure, uncertainty in the supply and pricing of 
Table 1: Applications of IMS in the pulp and paper industry

\begin{tabular}{||l|l||}
\hline \multicolumn{1}{|c|}{ Mills } & \multicolumn{1}{c|}{ Application } \\
\hline \hline $\begin{array}{l}\text { Alabama River Pulp Co. Inc. } \\
\text { (Perdue Hill, AL) [28] }\end{array}$ & $\begin{array}{l}\text { Processes are better synchronized, performance is tracked, and process } \\
\text { problems are better characterized }\end{array}$ \\
\hline $\begin{array}{l}\text { Georgia Pacific (Plattsburgh, } \\
\text { NY) [16] }\end{array}$ & $\begin{array}{l}\text { Systems are used for maintenance diagnosis, process troubleshooting, and } \\
\text { the tracking of grade specifications }\end{array}$ \\
\hline $\begin{array}{l}\text { Abitibi-Consolidated Inc. } \\
\text { (Jonquière, QC) [18] }\end{array}$ & $\begin{array}{l}\text { Instrument and control loop integrity are verified, and routine maintenance } \\
\text { tasks are streamlined }\end{array}$ \\
\hline $\begin{array}{l}\text { Abitibi-Consolidated Inc. } \\
\text { (several mills, ON) [20] }\end{array}$ & $\begin{array}{l}\text { Power consumption is monitored and planned to decrease cost in a } \\
\text { deregulated power market }\end{array}$ \\
\hline $\begin{array}{l}\text { Madison Paper Industries } \\
\text { (Madison, ME) [24] }\end{array}$ & $\begin{array}{l}\text { Business processes are supported and the financial performance is tracked in } \\
\text { real time }\end{array}$ \\
\hline
\end{tabular}

energy and raw materials, as well as the need for innovation in equipment and machinery. Solutions addressing these challenges would provide opportunity for industry rejuvenation, or at least competitive advantage. The availability of IMS data has given the pulp and paper industry an extra resource for tackling these very problems. Ritala [19] describes that process efficiencies, and especially capital and supply chain efficiencies are key to the pulp and paper industry. Ritala highlights key data-driven opportunities to achieve these goals including for example modeling and dynamic simulation as tools for studying process variability to reduce operational problems such as paper machine breaks. Advanced optimization based on real-time data can be used to improve production scheduling, and advanced process control strategies such as model predictive control can be used for automatic grade changes.

These changes are manifested in the corporate goals of leading pulp and paper companies. For example fine and specialty paper producer Domtar has announced five objectives for improving their performance as a company [4]. These objectives are to enhance customer loyalty, to double the size of the company, to improve productivity, to continue good citizenship, and to maintain the financial return edge. Information and knowledge can be extracted from the available data in order to reach these goals, for example:

- Enhancing customer loyalty requires a more flexible and a higher-performing delivery system, which can be obtained by the implementation of supply chain management (SCM).

- Doubling the size of the company is generally met by the acquisition of other companies, which in turn is possible by strong share prices. The stock market today insists on a strong Return on Capital Employed (ROCE) performance metric from pulp and paper sector companies - achieved through incremental production increases and operating price decreases from existing facilities which can be identified through a variety of process integration techniques. As well, tools such as life cycle assessment (LCA) can be used to illustrate excellence in environmental and energy performance from the product perspective and enhance share price from this perspective.

- For improving productivity, one needs to know the key impacts on the net profitability and performance of the mill processes, and be able to quantify these impacts through cost management and holistic process analysis. This can be facilitated by a holistic business model such as that described in this paper, and by analyzing product mixes using sophisticated applications of process integration based on supply chain modeling.

- Good citizenship can be achieved by combining environmental and social risk management with solid financial performance.

- In order to attract quality investors, Domtar seeks to maintain a financial return edge. Good financial returns can be measured in many ways, but are achieved by being perceived as providing a quality product for a reasonable price while having competitive production costs.

All of these goals can thus be addressed using process integration tools, and require multi-criteria decisionmaking based on a consistent set of data.

\subsection{Surveys on the use of IMS}

In 2002, an initial survey about the use of data management systems (DMS) in the pulp and paper industry was conducted amongst Canadian pulp and paper mills and vendors of data/information software [8]. A data management system is comprised of software that facilitates the creation and maintenance of databases for data acquisition and storage. Data management systems are one component of IMS. In 2003, another survey of American and Canadian mills was executed about the use of IMS in the pulp and paper industry [9]. These surveys confirm that huge 


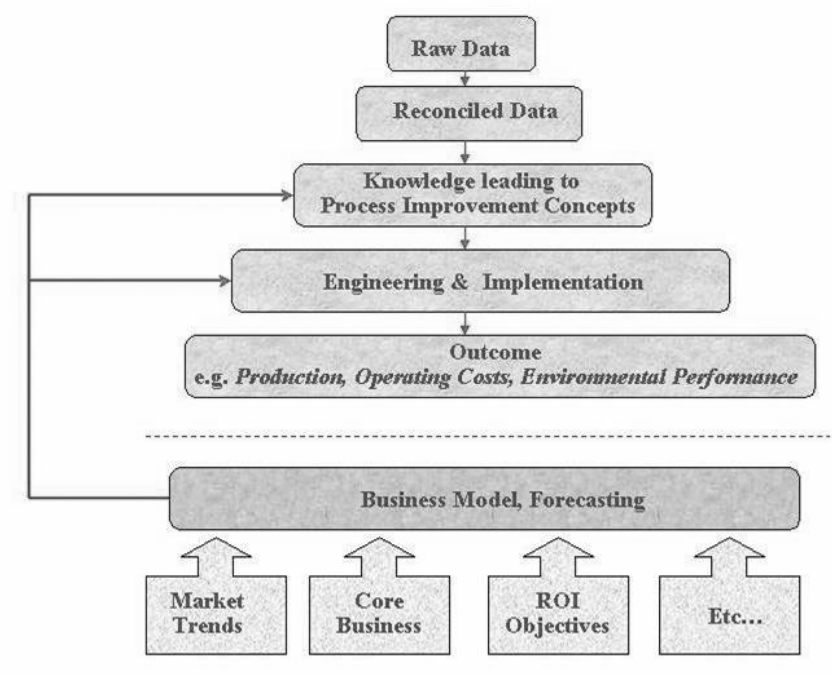

Figure 1: Classical engineering design process employed in the pulp and paper industry

datasets have been stored at pulp and paper mills and data are now widely available to mill personnel, but the true value of the data has yet to be fully exploited. Reasons for this include a lack of time and money to invest in this goal, and apprehension about how to systematically develop the correct systems and obtain a high return on investment. Despite these obstacles, the interpretation of data is still considered to be critical to the competitive position of mills. Furthermore, the surveys showed that until now, the benefits from using data are mostly related to the characterization and $a d$ hoc analysis of operations. A practice that is not yet common is the coupling of process and business data, through means such as real-time costing systems that make use of process data coming from the data management system.

This paper proposes a business model which is a holistic framework that can be used for process, business, and environmental decision-making.

\section{Novel business model concept}

\subsection{Classical process design in the pulp and paper industry}

The traditional design process in the pulp and paper industry is illustrated in Figure 1, and has involved many engineers at the mill and corporation. Today, the engineering capacity at both these levels has been drastically reduced. However in many ways, the engineering processes have not been adjusted to reflect these cut-backs.

Capital spending is based on increasingly sophisticated analyses of market trends, established core business areas, ROI objectives for shareholders, etc. These objectives and insights are relayed to mill managers and engineers, who in turn identify opportunities for design improvement consistent with company priorities. Many of these can potentially be systematically incorporated into the business model concept proposed here.

Process simulation results are combined with financial and accounting information in an ad hoc fashion in the classical design process, in order to identify the most economically viable design options. Cost data have not been tightly integrated with process data in most mills, and changes in process design or operations are perhaps not accurately reflected in millwide costs. By combining the production process and the accounting system into one model such as proposed here, their mill-wide correlation will be more precisely reflected.

Data compiled in the business model described in this paper combined with process integration tools for process analysis assist in the goal of despecialization, where one engineer is better able to understand data issues (e.g., cost, process and environmental) through to the outcomes (e.g., product quality, capital costs, operating cost changes) from process improvement projects.

\subsection{Overview of business model concept}

The business model proposed here utilizes cost, process and environmental data in conjunction with process design and operations analysis tools (see Figure 2). The analysis of processes for improvements in operations and design are executed using various process integration tools. 


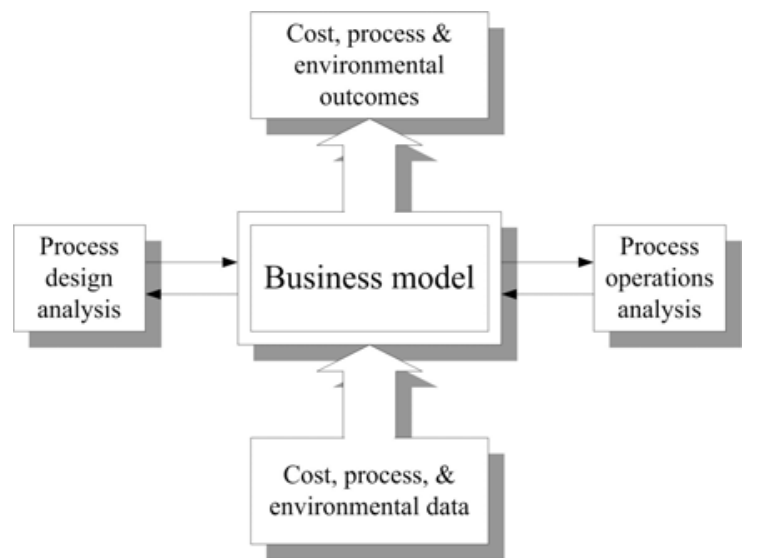

Figure 2: Dataflow between the business model and process design and operations analysis

Process integration (or process systems engineering) is a holistic approach for process design and operations, which emphasizes the unity of the process. It uses mathematical tools in conjunction with process expertise in order to extract information from the realtime data that are collected from different data sources. Real-time data are thus transformed into knowledge (through fundamental and empirical models), which can then be used for decision-making. The business model is facility-oriented and considers the operation of one mill and its products.

The center line in Figure 2 represents the transformation of raw real-time data into mill-wide knowledge via the business model. An expansion of the center line of Figure 2 is presented in Figure 3. The proposed business model concept can be divided in the following parts:

1. Data treatment activities which process and reconcile real-time process data, accounting data, and environmental data that are used in the business model.

2. Data input into models in which the process, economic and environmental data are utilized. Process data is also used in the accounting and environmental models. These models should ideally characterize the cost, process and environmental performance of individual mill areas.

3. Data input into product chain models in which the mill product(s) can be followed along the life cycle, and to which the businesses constituting the supply chain are included in the model.

It is possible to expand the model to a multi-site, company-wide model and to consider the overall supply chain in which the mill or company takes part.

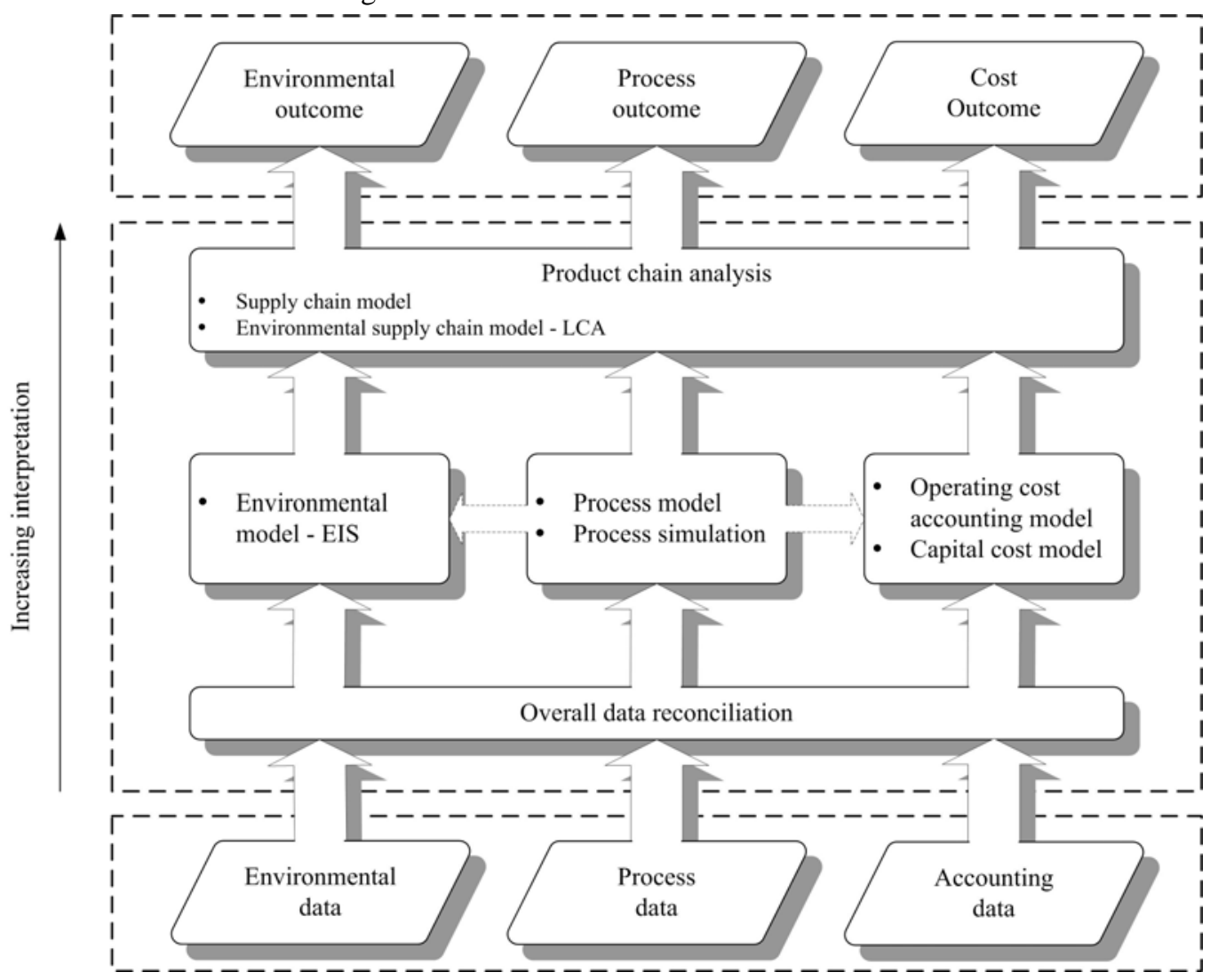

Figure 3: Schematic of the flow and processing of data within the proposed business model 
The business model is highly data-intensive. With the advent of IMS, this challenge has become less restrictive. However, data quality remains an issue. Also, since the business model uses historical data for making decisions for the future, uncertainty in the data plays an important role that needs to be taken into account for decision-making.

\subsection{Data treatment considerations}

Real-time process data must be mathematically processed (i.e., treated to eliminate noise and abnormalities). Measurement noise has frequencies much higher than normal process variations, whereas abnormalities are defined as spikes in the measurement with a supra-normal value and a short duration. A wavelet-based multi-scale data processing approach has been used to process pulp and paper mill data [11]. Next, steady state detection can be performed for the processed data set in order to identify near steady state operation. The treated steady-state process data can then be used in data reconciliation (also shown in [11]), so that gross errors are detected and the quality of the process data is increased. When these data processing and reconciliation steps have been executed many times over a long time period, a probability of occurrence can be established for each process parameter at each mill operating regime.

Next, the relationships between the process data and the accounting and environmental data can be modeled (see Figure 4). Using these relationships, an overall data reconciliation model is built and the reconciliation is performed in order to generate a single coherent and reliable data set. A feedback loop from the overall data reconciliation can be used for an iteration of the process data reconciliation and a revalidation of the accounting and environmental data until the desired coherency is attained, and can be used to update relationships based on on-line data acquisition and treatment. The coherent data set is used in the process, accounting, and environmental models of the business model.

\subsection{Process modeling aspects of the business model}

Process modeling can be performed based on first principles models, and/or based on data-driven empirical models. First principles modeling uses the energy and mass balances derived from the process under study [13]. Data-driven modeling uses available data in conjunction with inductive mathematical techniques such as neural network modeling or multivariate analysis (MVA) to generate empirical models [6]. Empirical modeling is often used when complex phenomena must be considered which do not lend themselves well to fundamental modeling. Often, in pulp and paper process modeling, these two approaches can be combined to form hybrid models.

\subsection{Activity Based Costing (ABC) accounting aspects of the business model}

Activity Based Costing (ABC) is a cost accounting method that first accumulates costs for each of the activities of an organization, and then assigns the costs of these activities to the products, services, or other cost objects that caused that activity [7]. The benefits of using $\mathrm{ABC}$ and $\mathrm{ABC}$-like accounting are numerous. Perhaps the most important is the ability to better allocate overheads when compared to traditional volume-based costing methods [5].

ABC differs from traditional volume-based costing systems in that [5]:

- Cost objects consume activities and these activities consume resources,

- $\mathrm{ABC}$ uses activity and resource drivers to trace costs to objects in a causal manner.

The ABC costing method is a model that is processoriented and is therefore a good alternative to apply for modeling and calculation of the operating costs of a process.

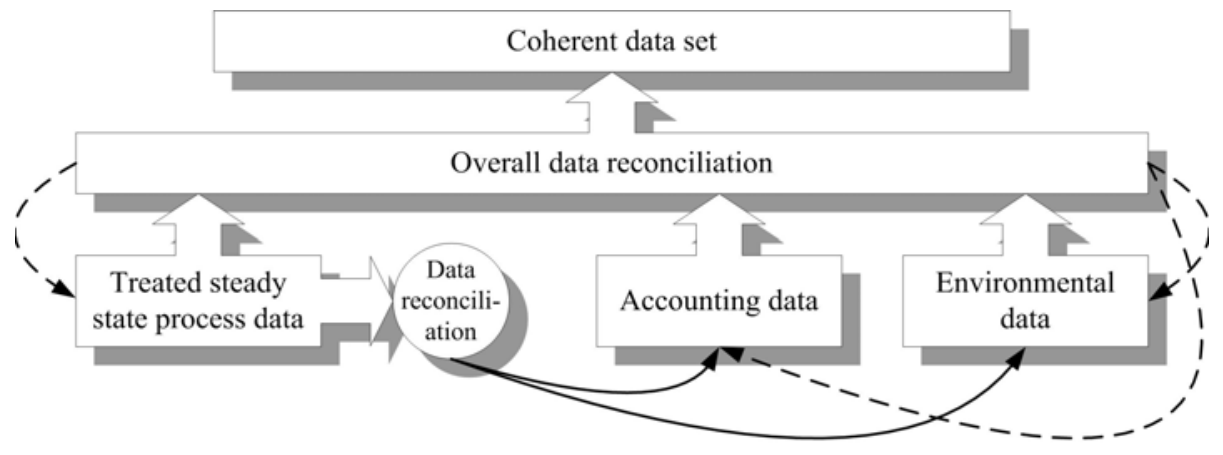

Figure 4: Data reconciliation of different types of data 
3C Software [1] is widely used in the pulp and paper industry and uses an approach by which the accounting system can be easily integrated with e.g. process control systems or product tracking systems. Yeager [27] discusses the implementation and use of the $3 \mathrm{C}$ product at a fine paper mill. An ABC-like cost model is used which is based on an object-oriented design. Overhead costs are better allocated, product costs are traced more accurately and optional cost scenarios can be run that show the financial implications.

\subsection{Life Cycle Assessment (LCA) aspects of business model}

Life Cycle Assessment (LCA) is used for the modeling of the site-generic environmental impact of a product. LCA can be used to examine the environmental aspects and potential impacts throughout a product's life cycle from raw material acquisition through production, use, and disposal [10].

LCA is a chemical engineering tool since it relies heavily on mass and energy balances and can be used to establish critical environmental performance indicators. It has been applied in process selection, design, and optimization for identifying clean technologies [3]. LCA, when applied correctly, can yield the best process option from an environmental perspective [2].

In the context of process design, the main advantage of using LCA lies with the ability to analyze the environmental performance of a proposed design using a broader perspective than more conventional approaches, such as Environmental Impact Assessments (EIA's) which are site-specific. LCA has been used effectively in the pulp and paper industry for examining design options, for example in Salazar et al. [21].

In general, a life cycle thinking approach in the pulp and paper industry is oriented towards the use of an LCA baseline model as an engineering tool to analyze process variants. Specifically, the following applications are currently being investigated [22]:

- Use of LCA for the demonstration of continuous environmental improvement in the context of Environmental Management Systems,

- Use of LCA for the assessment of major process modifications in the context of Environmental Impact Studies (EIS's), and

- Use of LCA for the investigation of minimum impact manufacturing configurations in the context of strategic process planning.

New LCA-based continuous environmental improvement metrics related to process operations will be developed by comparing the results of the baseline model for mill process data from different years. For the two latter applications, LCA can also be used as a comparison tool in order to assess the environmental benefits and impacts due to the transition of the baseline process to novel designed mill configurations.

\subsection{Supply chain modeling aspects of business model}

A supply chain is a "network of organizations that are involved, through upstream and downstream linkages, in the different processes and activities that produce value in the form of products and services in the hands of the ultimate customer" [25]. Supply chain modeling is an approach to modelling the network (the supply chain) that exists between a manufacturing facility and its suppliers and customers. The benefits of supply chain modeling are manifold:

- Better understanding of the supply chain itself,

- Better understanding of the needs of the customer,

- Achieving a strategic fit between the supply chain and competitive strategies, which means that the supply chain capabilities should match the competitive objectives,

- Increasing the performance of the supply chain by looking at its efficiency (the cost of making and delivering a product to the customer) and its responsiveness (the ability to respond to wide range of quantities, meet short lead times, handle a large variety, innovate and meet high service levels).

The supply chain model is used in the analysis and optimization of product chains for obtaining a better material flow, and is therefore a tool for supply chain management (SCM).

The supply chain model uses data coming from the process, cost, and environmental models in order to assess the influence of changing operating conditions or changing process design on the material flow throughout the supply chain.

\subsection{Using outcomes from the business model}

The outcomes from the business model (cost, process and environmental) are to be used in decision analysis. In engineering, decisions made on a corporate or facility level are typically profit-driven. With the business model, a thorough analysis can be executed to make well-informed decisions that reflect the preferences of the decision-makers, done with MultiCriteria Decision-Making (MCDM) techniques, for example Multi-Attribute Utility Theory (MAUT) which was developed by Keeney and Raiffa [12]. The 
trade-off between economic and environmental objectives can be determined by the assessment of decision weights.

\subsection{Future possibilities}

If such a business model were to be developed for a pulp and paper mill based on real-time cost, process and environmental data, the possibilities for its use in decision-making would be limited only by the imagination of corporate and mill management.

For example, incorporating variability or uncertainty in the data for decision making would permit design and operating decisions to be made based on operating parameter probabilities of occurrence and extreme values. Ultimately, the business model could evolve into a dynamic environment where decisions can be made in real-time using this data. For example, optimization techniques could be used to maximize the expected profit and simultaneously, to minimize the expected environmental impact for different operating regimes. Based on these calculations, design criteria can be defined such that Pareto-optimal regimes that simultaneously feature the highest profitability and the lowest environmental impact are maintained more easily.

Two other important issues that could be taken into account are the flexibility and feasibility of new process designs. A process design needs to meet feasibility criteria over a range of uncertain parameter values in order to guarantee safe and productive operations. In so doing, the flexibility of the process design needs to be taken into account as it indicates the capability of the process to achieve feasible operations. However, there is a trade-off between the flexibility and the cost of a process. This trade-off can be quantified with the business model.

The business model can be extended along the supply chain or a company-wide model can be constructed connecting several mills in one model. Flexibility and feasibility of the supply chain can thus be studied using real-time data and knowledge.

\section{Process design decision-making: Hypothetical case study}

In this hypothetical case study, the business model will be applied to a decision-making problem regarding process design changes at a hypothetical integrated newsprint mill. The specific problem will be a combination of the engineering of an existing De-Inked Pulp (DIP) plant with the goal of increasing DIPproduction, and the implementation of an on-site cogeneration plant at this mill. This is a retrofit problem in which the consequences of both projects on the existing mill are considered from a process, economic, and environmental perspective. The existing mill consists of:

- 4 paper machines with a production of 1100 admt/day of newsprint paper,

- 2 Thermo-Mechanical Pulp (TMP) lines that produce 925 admt/day,

- $\quad$ DIP production of $175 \mathrm{admt} /$ day.

The following process options have been defined:

- 550 admt/day DIP (1- or 2-loop configuration), $550 \mathrm{admt} /$ day TMP, $30 \mathrm{MW}$ cogeneration,

- 1100 admt DIP (100\% DIP) (1- or 2-loop configuration), 14.7 MW cogeneration.

The design changes are subject to environmental and economic targets. The business model and decisionmaking procedure will be tools for choosing the most preferred design.

Figure 5.a illustrates the procedure for using the real-time data and the business model for process design decision making. This procedure starts with the treatment and reconciliation of the data. These data are then used by process integration tools in order to construct process design options. Scenarios are developed for each of the design options and the business model is run to assess the performance of the scenarios both economically and environmentally and optimize this performance. The knowledge obtained in this step is then used in a decision analysis in order to determine the most preferred design.

The case study described in this section serves as a proof-of-concept for the general procedure and is illustrated by the simplified method in Figure 5.b. The first step in the case study is to execute a classical techno-economic study and Environmental Impact Study (EIS) of the process options for increased DIP production and cogeneration. During the technoeconomic study, sensitivity analyses are done. Key sensitivity parameters under review may be:

- DIP-plant: use of different technology (1-loop vs. 2-loop configuration), scale of operation, price volatility of waste paper,

- Cogeneration plant: use of natural gas vs. hog fuel,

- TMP-plant: amount and price of electricity used,

- Mill location: the location of the mill affects energy prices and transportation costs.

The characteristics of the developed process design options are transposed to the business model. The process is modeled based on first principles, the operating costs are modeled using ABC-like accounting principles. The environmental impact of the design options are modeled using LCA in order to also take into account environmental impacts due to the product chain. 


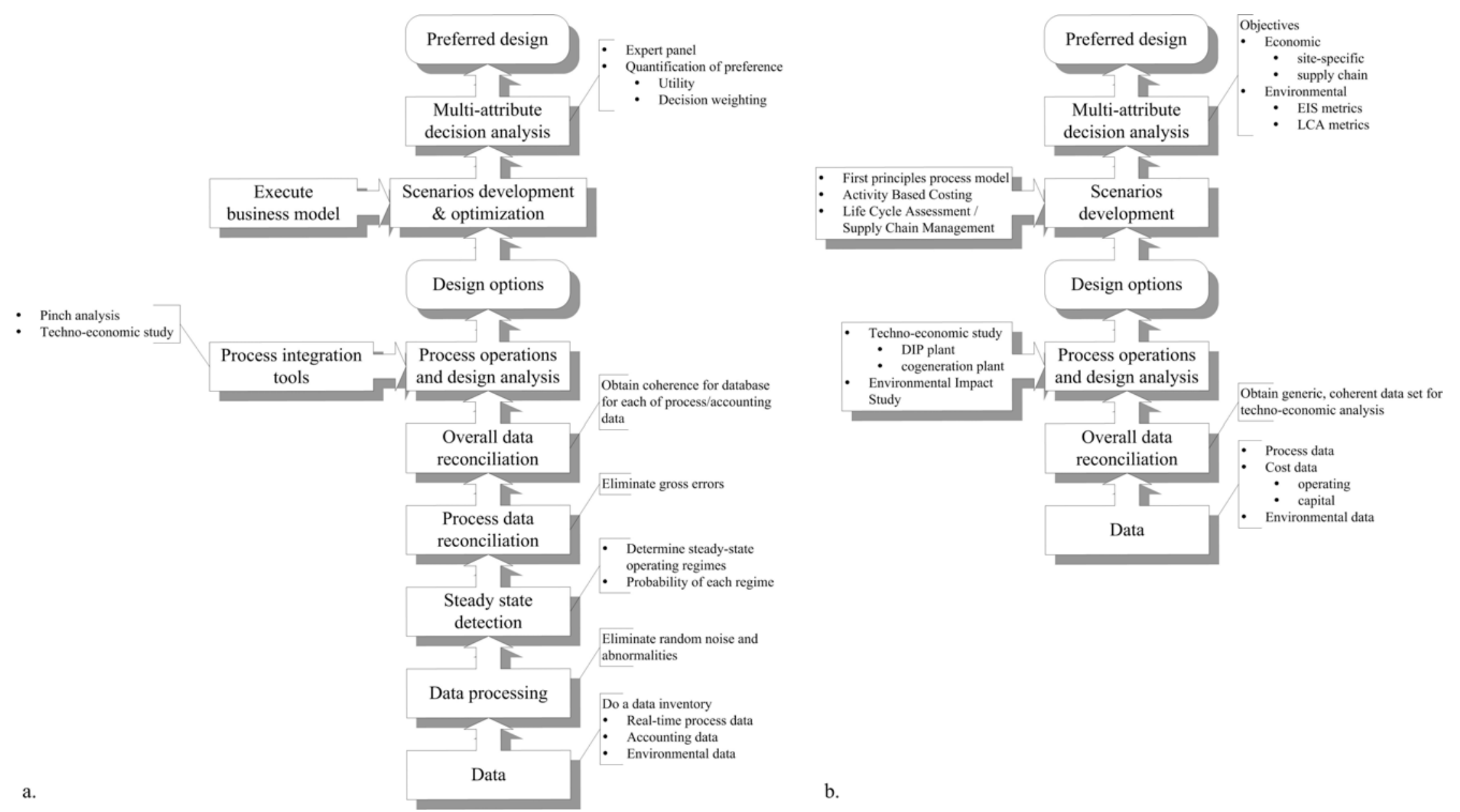

Figure 5: The "bottom-up" approach for using real-time data in process design: a. general procedure; b. case study procedure (proof-of-concept) 


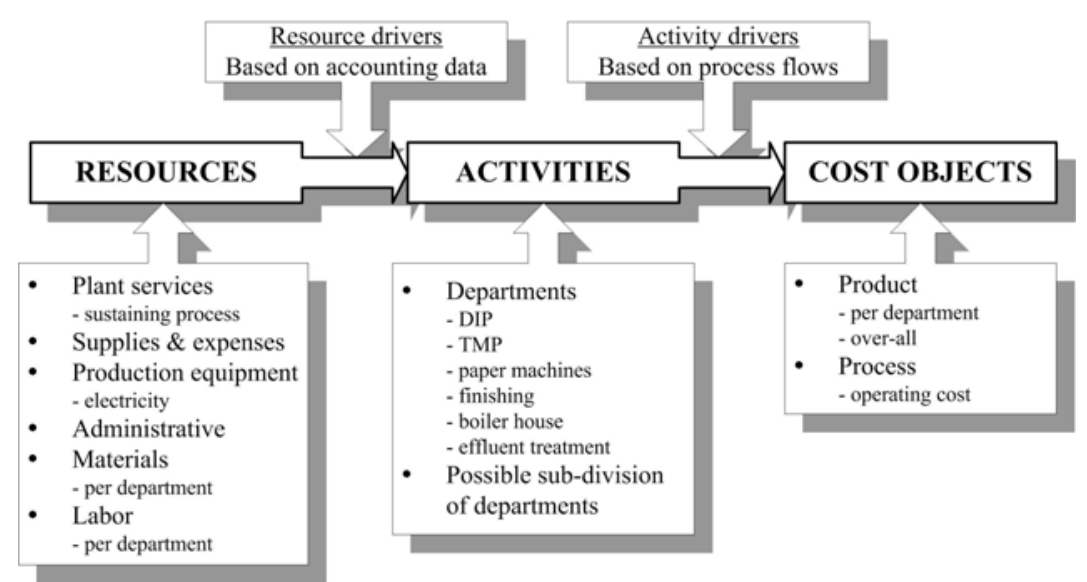

Figure 6: $A B C$ at an integrated newsprint mill

Furthermore, impacts on the supply chain due to the different design options are assessed with the help of a supply chain model.

Linking process parameters to parameters in the ABC-like accounting model and baseline LCA model is clearly critical in order to have consistent outcomes from the business model. For the example of cost accounting, it is important to know how the cost model parameters change with a changing process design or product (Figure 6). For instance, the activity drivers, which are calculated with the actual flows in a process, will be based on this kind of information. As with the ABC model, process parameters also need to be linked to parameters in the LCA. The LCA gives a productoriented view of the environmental impact and as such, it can be used to study the impacts of producing different products. Using scenario analysis, the flexibility of the process design is taken into account when ultimately deciding which design options to implement. For instance, ABC-like accounting can be used to calculate the marginal costs of running different scenarios with a given process design.

The decision structure for choosing the most preferred design is based on the trade-off between the economic and environmental objectives of the decision, as illustrated in Figure 7. Within each of these objectives, there are sub-objectives based on selected representative metrics. There are site-specific cost metrics (Net Present Value) and supply chain based cost metrics (e.g. transportation and inventory costs), as well as site-specific EIS-metrics (e.g. effluent concentrations) and more global and local LCAmetrics (e.g. respectively global warming potential (GWP) and acidification) for environmental objectives. The outcomes of the business model are used to determine these metrics.

\section{Conclusions}

In this paper, a framework was presented in which real-time process, cost, and environmental data can be used for process design purposes. A bottom-up approach, starting with these data and evolving to process design decision-making, was outlined and a hypothetical case study situated at a pulp and paper mill was used to illustrate its application.

It is clear that the implementation of information

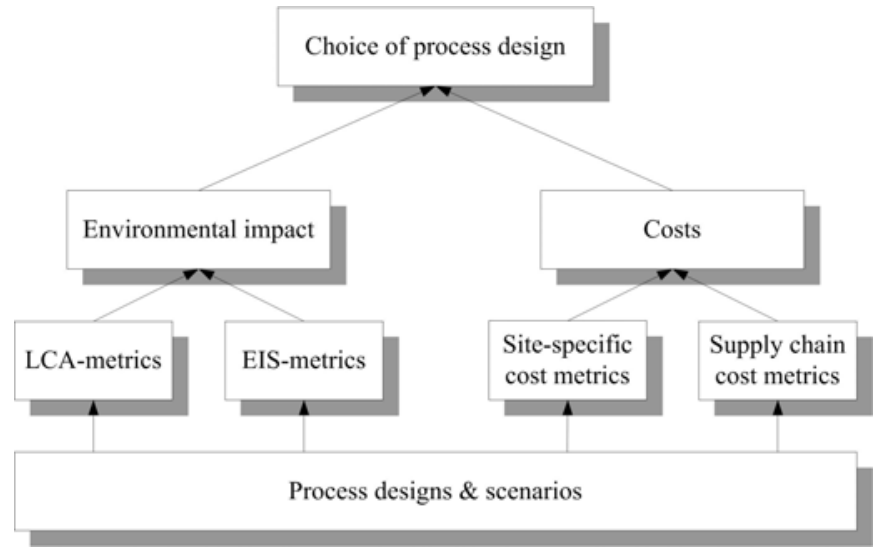

Figure 7: Decision structure for process design decision-making 
management systems at pulp and paper mills has opened up opportunities for innovation by making available massive amounts of data. However, the full potential of this data is not being fully exploited. The proposed business model is based on real-time process data and a bottom-up approach. It uses a rigorous reconciliation of process, cost, and environmental data in order to relate the different sources of these data. By using a process model and linking it with an ABC-like accounting model, decisions can be made with which the marginal costs of the operations can be improved. Both LCA and supply chain management are used to determine the environmental implications of the product along the supply chain.

Using the business model for process design purposes has several benefits. By reconciling process, cost and environmental data simultaneously, clear relationships are constructed between the data and a coherent data set is formed. ABC-like accounting will provide a more detailed costing model for determining operating costs for different process scenarios. More global aspects such as supply chain issues and issues concerning global environmental impact (LCA) can be taken into account in the process design.

\section{Acknowledgements}

This work was supported by the Natural Sciences and Engineering Research Council of Canada (NSERC) Environmental Design Engineering Chair at École Polytechnique.

\section{References}

[1] 3C Software. 3C Software Home Page. 2004. 2004.

[2] Azapagic, A., Life cycle assessment and its application to process selection, design and optimisation Chemical Engineering Journal, vol. 73, no. 1, pp. 1-21, Apr, 1999.

[3] Chevalier, J., Rousseaux, P., Benoit, V., and Benadda, B., Environmental assessment of flue gas cleaning processes of municipal solid waste incinerators by means of the life cycle assessment approach Chemical Engineering Science, vol. 58, no. 10, pp. 2053-2064, May, 2003.

[4] Domtar Inc., Montréal, Canada, 2003.

[5] Emblemsvåg, J. and Bras, B., Activity based cost and environmental management - A different approach to the ISO 14000 compliance, 2001. Kluwer Academic Publishers. Norwell, MA, USA.

[6] Harrison, R. P., Leroux, R., and Stuart, P. R., Multivariate analysis of refiner operating data from a TMP newsprint mill Pulp \& Paper Canada, vol. 105, no. 4, pp. 24-27, 2004.

[7] Horngren, C. T., Sundem, G. L., Stratton, W. O., and Teall, H. D., Management Accounting 3rd edition, 1999. Prentice Hall Canada Inc. Scarborough, ON, Canada.

[8] Janssen, M., Laflamme-Mayer, M., and Stuart, P.,
"Survey of data management systems used in the pulp and paper industry," FOCAPO 2003: Proceedings Foundations Of Computer Aided Process Operations, Coral Springs, FL, USA, pp. 551-554, 2003.

[9] Janssen, M., Laflamme-Mayer, M., Zeinou, H. M., and Stuart, P., Using IMS Data in the Pulp and Paper Industry Pulp \& Paper, vol. 105, no. 6, pp. ?? 2004.

[10] Jensen, A. A. e. al., dk-TEKNIK Energy \& Environment/European Environment Agency (EEA), Søborg, Denmark, 1997.

[11] Jiang, T., Chen, B., Jasim, K., and Stuart, P., "Strategy for improving data quality for a Kraft pulp mill recausticizing plant," FOCAPO 2003: Proceedings Foundations Of Computer Aided Process Operations, Coral Springs, FL, USA, pp. 467-470, 2003.

[12] Keeney, R. L. and Raiffa, H., Decisions with multiple objectives: Preferences and value trade-offs, 1976. John Wiley \& Sons, Inc. New York.

[13] Lafourcade, S., Labidi, J., Koteles, R., Gélinas, C. , and Stuart, P., Thermal pinch analysis with process streams mixing at a TMP-newsprint mill Pulp \& Paper Canada, vol. 104, no. 12, pp. 74-77, 2003.

[14] Leaver, E. W. and Scott, S. E., Rejuvenation: Challenges and opportunities in the pulp and paper industry Pulp and Paper Canada, vol. 104, no. 4, pp. 14-17, 2003.

[15] OsiSoft. OsiSoft. 2004. 2004.

[16] Osisoft, Inc. Georgia Pacific. http://www.osisoft.com/5_151.aspx . 2002. 2003.

[17] PeopleSoft, Inc. PeopleSoft. 2004. 2004.

[18] Pulp \& Paper Canada Special Report, Asset management software becomes first tool used by maintenance technicians Pulp and Paper Canada, vol. 103, no. 4, pp. 17-19, 2002.

[19] Ritala, R., "Plenary lecture: Modeling, simulation and optimization in paper industry ," ESCAPE-13, Helsinki, Finland, 2003.

[20] Roussel, G., Real-time process data optimized electricity purchasing Pulp \& Paper Canada, vol. 104, no. 12, pp. 1619, 2003.

[21] Salazar, E. , Samson, R., Munnoch, K., and Stuart, P. R., Identifying Environmental Improvement Opportunities for Newsprint Production Using Life Cycle Assessment (LCA) Submitted for publication in TAPPI Journal, vol. 2004.

[22] Salazar, E., Samson, R., and Stuart, P. R., Development of an LCA Baseline Model for Newsprint Production To be submitted to International Journal of LCA, vol. 2004.

[23] SAP AG. SAP. 2003. 2004.

[24] Shaw, M., Fast-track ERP project integrates business functions for Madison Paper Industries Pulp and Paper, vol. 77, no. 8, pp. 28-30, 2003. 0033-4081.

[25] Stadtler, H. Supply chain management - An overview. In: Supply chain management and advanced planning, eds. Stadtler, H. and Kilger, C. Berlin, Germany: Springer Verlag, 2000.pp. 7-28.

[26] TietoEnator. MOPS Systems. 2003. 2004.

[27] Yeager, B., Costing software helps Sappi Mills make the grade more efficiently Pulp \& Paper, vol. 73, no. 12, pp. 63-66, 1999.

[28] Yeager, R., Information system coordinates operation at Alabama River market pulp complex Pulp \& Paper, vol. 72, no. 2, pp. 97, 98, 101-103, 1998. 